\title{
APPROXIMATE SOLUTIONS FOR TWO DIMENSIONAL PROBLEMS IN WATER POLLUTION - COMPONENT SUPPRESSION SCHEMES
}

Jorge R. S. Zabadal

Departamento de Engenharia Nuclear

UFRGS -Porto Alegre, RS

\section{RESUMO}

No trabalho a seguir é proposto um novo método híbrido para a resolução de problemas em poluição aquática. O método fornece soluções aproximadas em forma analítica para a equação de transporte bidimensional, para situações nas quais o acoplamento entre os modelos hidrológico e de transporte pode ser ignorado. A alta velocidade de processamento do esquema híbrido permite simular a dispersão de poluentes em tempo real, empregado microcomputadores de baixa performance.

\section{ABSTRACT}

In this work a new hybrid method for solving problems in water pollution is proposed. The method furnishes approximate solutions for the two-dimensional transport equation in analytical form, in cases when the coupling between the hydrological and transport models can be neglected. The high speed processing of the scheme allows to simulate the transient dispersion in real time using low performance microcomputers. 


\section{1 -INTRODUCTION}

The formal solution of two dimensional problems in transport theory often requires a large ammount of analytical handling or time processing to be transformed in a practical result. In water pollution problems, an approximation in analytical form is useful for evaluating the evolution of concentration profiles in real time, either to obtaining numerical results or to analize the dynamical behavior of the hydric corp in a qualitative way.

The formal solution is the starting point for many numerical and analytical methods used to solve transient problems, which usually involves the evaluation of high powers of evolution operators. Successive powers of an evolution operator, when applied on the function describing the initial state of the system, provides the successive states of the system along the time.

For some practical applications, the calculation of successive states of the system are not necessary, being desirable to skip time steps in order to reach the final state as fast as possible. In most practical water pollution problems, there is no necessity to determine with high precision the concentration of the pollutant and the shape of the affected area in order to prevent damages on regions of special interest.

This work presents a method for obtaining approximate solutions for water pollution problems in analytical form. The method consists in fitting functions of operators, present in the formal solution, by polynomials. The functions are fitted in an interval containing the eigenvalues of the spatial operator, which are estimated indirectly by variational formulations recently developed. These formulations follows from the idea of component suppression, proposed in the universal alghoritms for solving linear algebraic systems [1], and extend its applications to ill-posed problems in infinite dimensional space. The main features of these formulations are the high speed proccessing and the independence of a priori information about the desired solution, which is required for the most usual methods employed for solving ill-posed problems [2]. Some hybrid methods based on analogous 
formulations were applied succesfully in Chemistry and Transport Theory (reactor modelling and neutron scattering [3-8]). A numerical simulation is reported.

\section{2 -GENERAL DESCRIPTION}

Consider the following operator equation

$$
\mathrm{Af}=\frac{1}{\mathrm{c}} \frac{\partial \mathrm{f}}{\partial \mathrm{t}},
$$

where $\mathrm{A}$ is a linear operator, $\mathrm{t}$ denotes the time and $\mathrm{c}$ is a numerical constant. The corresponding initial condition is $f(r, 0)=f_{0}(r)$, in which $r$ denotes the spatial coordinates, and the medium is taken as infinite (there is no boundary conditions). The formal solution for this problem is given by

$$
\mathrm{f}=\mathrm{e}^{\mathrm{cAt}} \mathrm{f}_{0}
$$

The McLaurin series in the time variable, truncated in the linear term, produces a solution valid for small values of $\mathrm{t}$ :

$$
\mathrm{f} \cong(\mathrm{I}+\mathrm{c} \Delta \mathrm{tA}) \mathrm{f}_{0}=\mathrm{Ef}_{0}, \quad 0<\Delta \mathrm{t}<<1,
$$

where I denotes the identity operator and $\Delta$ t represents a small time interval. In this equation appears the evolution operator $E$, whose successive powers applied on $f_{0}$ furnishes the states of the physical system along the time, which constitutes approximations for the formal solution:

$$
\mathrm{f} \cong \mathrm{E}^{\mathrm{k}} \mathrm{f}_{0}
$$

The powers $E^{k}$ can be approximated by a polynomial in the interval containg the spectrum of $E$ :

$$
\mathrm{E}^{\mathrm{k}} \cong \mathrm{p}_{\mathrm{n}}(\mathrm{E}) \quad \text {, }
$$

where $\mathrm{n}$ is the degree of the polynomial. Since $\Delta t$ is small, the eigenvalues of $E$ are concentrated in a small interval around 1, unless $A$ being unbounded. 
Although the most usual operators in physics being unbounded, because physical problems are usually described by differential equations, there is a practical way to overcome this difficulty. It consists in approximating the integer order derivatives by fractional ones whose order are slightly lower:

$$
\frac{\partial^{\mathrm{m}}}{\partial \mathrm{u}^{\mathrm{m}}} \cong \frac{\partial^{\mathrm{m}-\mu}}{\partial \mathrm{u}^{\mathrm{m}-\mu}}, \quad 0<\mu<<1 .
$$

The numerical value of $\mu$ depends upon the desired accuracy. As $\mu$ tends to zero, the spectral radius of $E$ grows, and the contributions of the associated eigenfunctions to the final solution are progressively included in the approximation. Replacing $E$ in equation (5) by the corresponding bounded operator B, obtained by means of the fractional derivative approximation, and substituing in (4), the approximated solution for the transient problem becomes

$$
\mathrm{f} \cong \mathrm{p}_{\mathrm{n}}(\mathrm{B}) \mathrm{f}_{0}
$$

The coefficients of the polynomial are obtained via least square fitting from an equally spaced set of points in the interval (1-c $\Delta t \rho, 1+c \Delta t \rho)$, where $\rho$ is the spectral radius of $A$ or its fractional derivative approximation, when $A$ is unbounded.

For steady problems, the treatment is slightly different, but follows from the same basic idea of the universal alghoritms. Consider now the stationary equation

$$
\mathrm{Af}=\mathrm{g}
$$

where $\mathrm{g}$ is a forcing function. The formal solution of equation (8) can also be approximated by means of component suppression, since

$$
\mathrm{f}=\mathrm{A}^{-1} \mathrm{~g} \cong \mathrm{r}(\mathrm{A}) \mathrm{g},
$$

where $r(x)$ represents a polynomial which approximates $1 / x$ in the interval containing $\operatorname{spec}(A)$. Applying the operator $A$ on both sides of equation (9), it results 


$$
\text { Af }=g \cong \operatorname{Ar}(A) g
$$

or

$$
\mathrm{g} \cong \mathrm{p}(\mathrm{A}) \mathrm{g} \quad \text {, }
$$

where $p(A)$ is a polynomial without independent term. This means that the original problem $A f=g$ becomes a curve fitting, in which $g$ is approximated by a linear combination of known functions, i.e.

$g \cong c_{1} A g+c_{2} A^{2} g+\ldots+c_{n} A^{n} g=c_{1} g_{1}+c_{2} g_{2}+\ldots+c_{n} g_{n}$.

The coefficients of the linear combination are determined by choosing $n$ collocation points in the domain and solving the resulting linear algebraic system:

$$
\left.\left.\mathrm{g}_{\mathrm{j}}\left(\mathrm{p}_{\mathrm{i}}\right)\right] \mathrm{c}_{\mathrm{i}}\right]=\left[\mathrm{g}\left(\mathrm{p}_{\mathrm{i}}\right)\right] \text {. }
$$

In this system, $\mathrm{p}_{\mathrm{i}}$ denotes the coordinates of the $\mathrm{i}^{\text {th }}$ collocation point and the index $\mathrm{j}$ specifies the function of the linear combination. Once obtained the coefficients $c_{i}$, the approximate solution is explicitly determined by applying the inverse operator $A^{-1}$ on (12):

$$
\begin{aligned}
& f \cong c_{1} g+c_{2} A g+\ldots+c_{n-1} A^{n-1} g \\
& A^{-1} \cong c_{1} I+c_{2} A+\ldots+c_{n-1} A^{n-1}=P
\end{aligned}
$$

Hence, a polynomial approximation for $\mathrm{A}^{-1}$ is given by

This operator is used to improve the solution obtained. A perturbation operator $\Delta \mathrm{P}$ can be defined in such a way that

$$
\mathrm{A}(\mathrm{P}+\Delta \mathrm{P})=\mathrm{I}
$$

or

$$
\mathrm{A} \triangle \mathrm{P}=\mathrm{I}-\mathrm{AP} \text {. }
$$

Therefore, a polynomial approximation for $\Delta \mathrm{P}$ is obtained if $\mathrm{P}$ is applied on both sides of (17):

$$
\Delta \mathrm{P}=\mathrm{A}^{-1}(\mathrm{I}-\mathrm{AP}) \cong \mathrm{P}(\mathrm{I}-\mathrm{AP}),
$$


and a new approximation for $A^{-1}$ arises:

$\mathrm{P}_{1}=\mathrm{P}+\mathrm{P}(\mathrm{I}-\mathrm{AP})=\mathrm{P}(2 \mathrm{I}-\mathrm{AP})$

The proccess can be repeated, generating a recurrence relation in the form

$\mathrm{P}_{\mathrm{k}+1}=\mathrm{P}_{\mathrm{k}}\left(2 \mathrm{I}-\mathrm{AP}_{\mathrm{k}}\right)$

In practice, this proccess never exceeds two iterations $(k<2)$, and frequently equation (14) provides a good aproximation for the concentration profile.

\section{3 -ERROR ANALYSIS}

The error in the proposed solutions can be estimated by means of the general component suppression alghoritm. In the steady problem, when the forcing function $g$ is expanded in the eigenfunctions of $A$, the expression for the resulting error is readily obtained. Rewritting $g$ as

$$
\mathrm{g}=\sum \mathrm{a}_{\mathrm{i}} \mathrm{h}_{\mathrm{i}} \text {, }
$$

where $h_{i}$ denotes the eigenfunctions of the operator $A$, the exact solution $f$ and the approximated one $f_{i}$ results

$$
\mathrm{f}=\sum \frac{\mathrm{a}_{\mathrm{i}}}{\lambda_{\mathrm{i}}} \mathrm{h}_{\mathrm{i}}
$$

and

$$
\mathrm{f}_{1}=\sum \mathrm{a}_{\mathrm{i}} \mathrm{p}\left(\lambda_{\mathrm{i}}\right) \mathrm{h}_{\mathrm{i}}
$$

in which $\lambda_{i}$ represents the eigenvalues associated to the eigenfunctions $h_{\mathrm{i}}$. The error in the approximated solution yields

$$
\mathrm{e}=\mathrm{f}_{1}-\mathrm{f}=\sum \mathrm{a}_{\mathrm{i}}\left[\mathrm{p}\left(\lambda_{\mathrm{i}}\right)-\frac{1}{\lambda_{\mathrm{i}}}\right] \mathrm{h}_{\mathrm{i}}
$$

Thus, the accuracy of the fitting polynomial $p(x)^{\sim} 1 / x$ determines the error of the approximation. For transient problems, when the calculation of the power 
$\mathrm{k}$ of the evolution operator is required, the polynomial must represent the function $x^{k}$ instead of $1 / x$. In the general case, the error is given by

$$
\mathrm{e}=\sum \mathrm{a}_{\mathrm{i}}\left[\mathrm{p}\left(\lambda_{\mathrm{i}}\right)-\phi\left(\lambda_{\mathrm{i}}\right) \mathrm{h}_{\mathrm{i}} \quad,\right.
$$

where $\phi$ represents the function to be applied on the operator. For instance, if a transient problem is solved directly from equation $(2), \phi\left(\lambda_{i}\right)=\exp \left(\lambda_{i}\right)$, because the exponential of the operator is required to obtain the corresponding formal solution.

\section{4 - RESULTS AND DISCUSSION}

The method were used to simulate an outflow of methanol in Guaiba river, a hidric corp employed in transport of petrochemicals (see figure 1). Initially, 200 tons of methanol are discharged around the position indicated by the arrow. The initial isocurves are considered circular, and the radial dependence of the concentration is approximated by a gaussian profile. The two-dimensional model adopted to describe the problem is given by

$$
\mathrm{D}\left(\frac{\partial^{2} \mathrm{c}}{\partial \mathrm{x}^{2}}+\frac{\partial^{2} \mathrm{c}}{\partial \mathrm{y}^{2}}\right)-\mathrm{u} \frac{\partial \mathrm{c}}{\partial \mathrm{x}}-\mathrm{v} \frac{\partial \mathrm{c}}{\partial \mathrm{y}}-\mathrm{kc}=\frac{\partial \mathrm{c}}{\partial \mathrm{t}},
$$

subjected to the initial condition $c(x, y, 0)=\exp \left\{-.05\left[\left(x-x_{c}\right)^{2}+\left(y-y_{c}\right)^{2}\right]\right\}$, where $x_{0}$ and $y_{0}$ represents the coordinates of the center of the isocurves. In equation (26), $c$ is the concentration, D is the effective difusion coefficient and $k$ is the decay constant. The components $u$ and $v$ of the velocity vector (in $x$ and $y$ directions respectively) are established beforehand, and considered constant for small regions along the flow. The discretization of $u$ and $v$ is necessary to carry out the linearization of equation (26), and imposes a restriction on the application of the method. When the load of pollutant is sufficiently large to produce perturbations on the velocity field, or in other cases when the coupling between the hidrodynamic and transport equations must be taken into account, the method becomes unpractical, since it demands several 
linearizations along the time, reducing considerably the processing speed of the system.

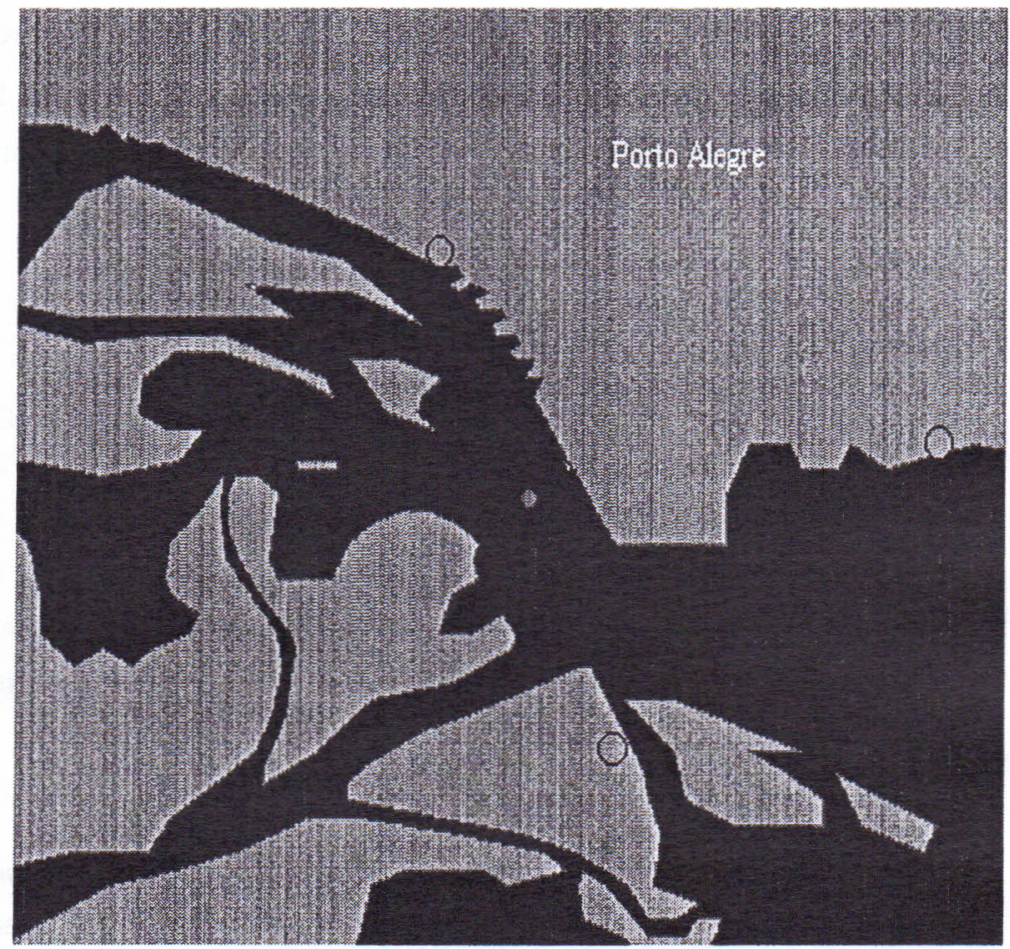

Figure1 -Position of the outflow

The concentration profiles after 7 and 15 hours are depicted, respectively, in figures 2 and 3 . These results are qualitatively consistent with experimental data related to the dispersion of coliforms $[7,8]$, whose parameters $D$ and $k$ differs from those for methanol, although the mechanisms 
of propagation being essentially the same. It is important to emphasize that the time processing required allows to furnish results on-line, once the average time for simulating $10 \mathrm{~h}$ of propagation is approximately 5 minutes, running in VB 5.0 and using a Pentium $166 \mathrm{MHz}$.

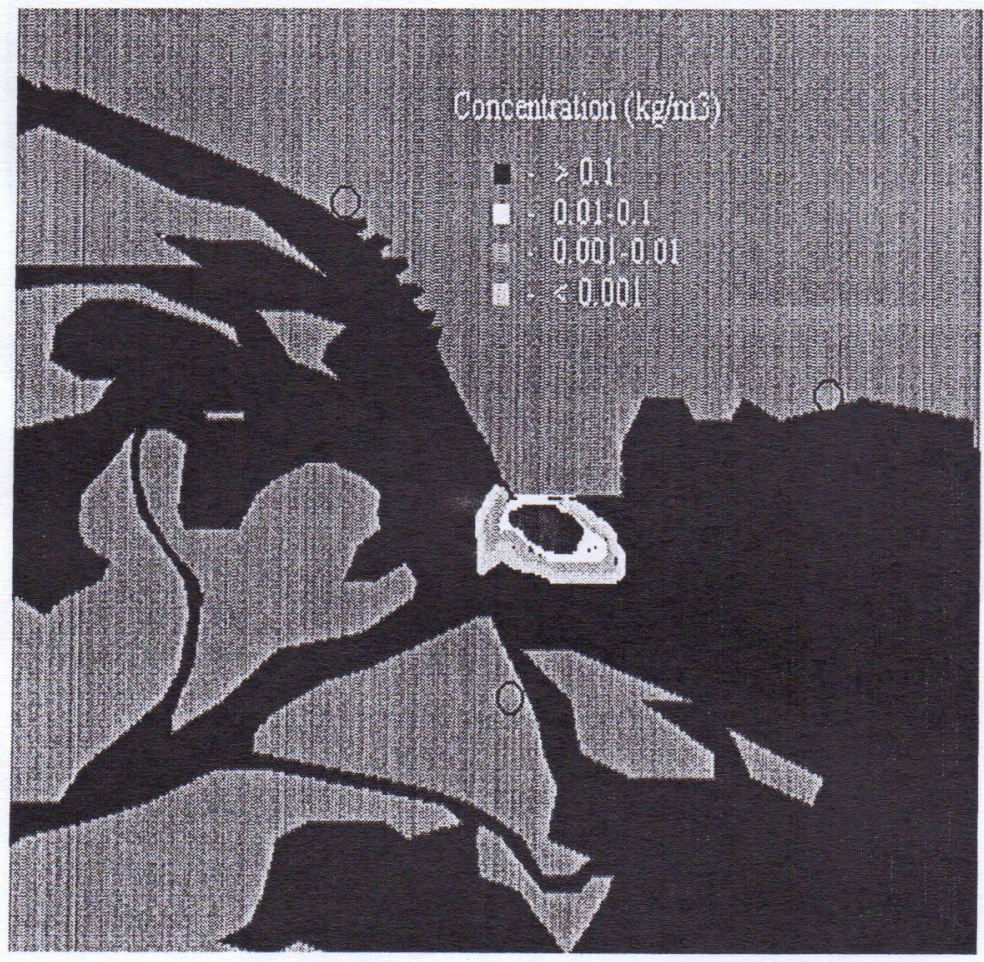

Figure 2 -Concentration profile after 7 hours 


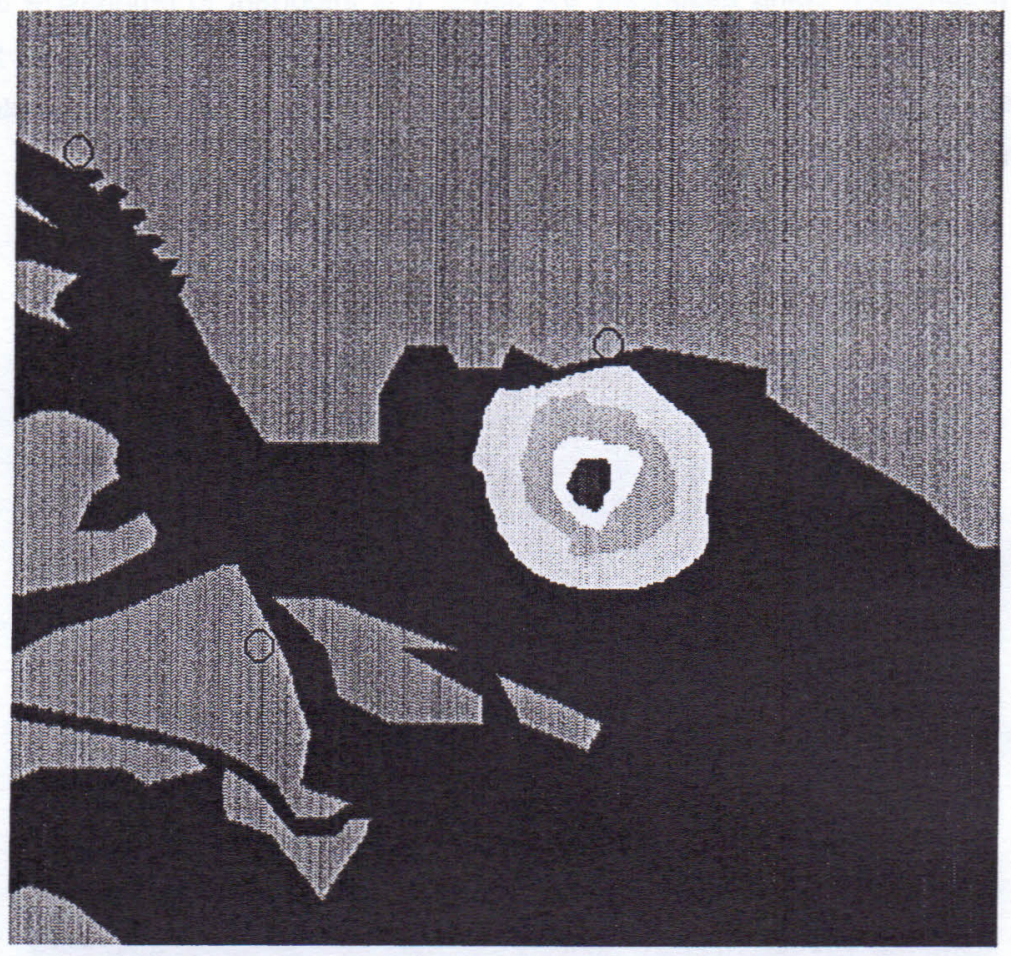

Figure 3 - Concentration profile after 15 hours

34 Rev. Ciência e Natura, Santa Maria, 22: $25-36$, 2000. 


\section{5 - CONCLUSIONS}

The proposed method, based on the component supression schemes, which were originally conceived for discrete formulations, is also applicable to infinite-dimensional problems. The main feature of the method is the low time processing required to evaluate the successive concentration distributions (about 5 minutes for simulating $10 \mathrm{~h}$ of propagation). However, the velocity field must be known beforehand, in order to provide the linearity of the advective terms in the transport equation. Hence, the method cannot be applied in cases where the coupling between the hidrodynamic and propagation models must be considered. 


\section{6 - REFERENCES}

[1] - Faddeev, D., Faddeeva, V. - Computational methods of linear algebra W. H. Freeman and Company, San Francisco (1963).

[2] - Tikhonov, A., Goncharsky, A., Stepanov, V., lagola, A. - Numerical methods for ill-posed problems -Nauka, Moscou (1990).

[3] - Zabadal, J., Vilhena, M., Barichello, L. - Solution of the ThreeDimensional One-Group Discrete Ordinates Problems by the LTSn Method Annals of Nuclear Energy, v. 22 p. 131-134 (1995).

[4] - Zabadal, J., Vilhena, M., Barichello, L. - An analytical solution for the two dimensional discrete ordinates problem in a convex domain - Progress in Nuclear Energy, v. 31, p. 225-228 (1997).

[5] - Zabadal, J. -Rio Guaiba - hidrodinâmica e propagação de coliformes Departamento Municipal de Água e Esgotos - Divisão de Pesquisa, Porto Alegre (1996).

[6] - Zabadal, J. - Propagação de bactérias e substâncias químicas no rio Guaíba -Departamento Municipal de Água e Esgotos -Divisão de Pesquisa, Porto Alegre (1991).

[7] - Böhm, L. - Modelo matemático de dispersão de bactérias Departamento Municipal de Água e Esgotos - Divisão de Pesquisa, Porto Alegre (1981).

[8] - Zabadal, J. - Reformulação do sistema HAR03 para dispersão de bactérias e oxigênio - Departamento Municipal de Água e Esgotos -Divisão de Pesquisa, Porto Alegre (1992). 